\title{
Special Needs Teachers' Perceptions on the Psychometric Test
}

\author{
Athina Mourelatou \\ ORCID: 0000-0003-1611-9308 • ResearcherID: V-8216-2017 \\ Milen Zamfirov \\ ORCID: 00oo-0003-2231-015X • ResearcherID: V-8511-2017 \\ Sofia University "St. Kliment Ohridski" \\ Faculty of Preschool and Primary School Education
}

Received 10 November 2017 • Revised 17 December 2017 • Accepted 20 December 2017

\section{Abstract}

In this survey a presentation of the difficulties of students with mild intellectual disabilities is performed. Intellectual disability is a neurodevelopment diagnosis and it refers to children who have developmental, adaptive behavioural and cognitive difficulties compared to their peers. Intellectual disabilities are categorized by their severity into: mild, moderate, severe, or profound. The purpose of this research is to construct a psychometric instrument for detecting intellectual disabilities in high school and specifically high school students aged 13-17. In order to find out if the specific psychometric test is appropriate to detect Intellectual disability, questionnaires have been given to special needs teachers. The research findings illustrate that the specific psychometric test is appropriate in order to detect intellectual disability.

Keywords: intellectual disability, psychometric test, detection, teachers' perception.

\section{Introduction}

Intellectual disability is referred in the international literature as intellectual subnormality, developmental disabilities, feeblemindedness, idiocy. It is considered as one of the most serious disadvantages in the spectrum of developmental disorders. Intellectual disabilities are categorized by their severity into: mild, moderate, severe, or profound. Intellectual disability is defined in various ways, which include learning, social and biological characteristics. Although it was first appeared in ancient times, however, until now, it is almost a modern unsolved pedagogical problem.

The primary objective of the design of the psychometric tool is, on the one hand, to build a simple, easy-to-use, fast and pleasant tool that can be used by teachers and, on the other hand, to deliver a simple and easy evaluation of the probability of existence intellectual developmental disorder.

Secondly, a profile of strengths and weaknesses should be created, which can be used as the basis for a possible future improvement.

(C) Authors. Terms and conditions of Creative Commons Attribution 4.0 International (CC BY 4.0) apply. Correspondence: Athina Mourelatou, Chrisostomou Smirnis 76, 65404, Kavala, Greece. E-mail: athina_mour@hotmail.com. 
In addition, this research was also conducted in order to examine the views of the teachers whether the particular psychometric tool is capable of diagnosing a potential intellectual disability.

- Detection of intellectual disability.

- Teachers' perception on memory detection.

- Teachers' perception on intellectual detection.

- Teachers' perception on mathematical characteristic detection.

- Teachers' perception whether the specific psychometric tool can help in diagnosing intellectual disabilities. formulated:

Being supported both by theory and research, the following research questions are

- Is it possible to diagnose intellectual disability by using the specific psychometric tool?

- Can the specific psychometric tool diagnose difficulties in students' linguistic development?

- Can the specific psychometric tool diagnose difficulties in students' mathematical development?

\section{Methodology \\ 2.1.1 Research access}

In this research, a deductive approach was used. The survey used the literature to move from general theories and ideas, to more specific results by using data. According to Saunders et al. (2003) deduction emphasizes is: a structured approach, quantitative collectiveness, moving from the general theory to more specific data, scientific approaches, to certify the validity of data with the appropriate controls, and the independence of the researcher concerning what is being researched and necessity to select samples.

\subsubsection{Research design}

A survey strategy was used for the specific research. According to Saunders et al. (2003) a survey strategy is appropriate for the deductive approach. Surveys help the researcher to collect a large amount of data from a substantial teaching population regarding their educational beliefs. They can be obtained through questionnaires and the data is standardised allowing the researcher to compare them easily. Moreover, using a survey strategy gives more control over the research process. Denscombe (2003) state that, questionnaires are an appropriate data collection method that belongs to the survey research strategy.

\subsubsection{The collection of primary data using questionnaires}

In order to collect the research data and to understand the relevance of the research process on the research issue, questionnaires were used. According to Rugg and Marian (2007), the questionnaire is a tool for communication. Using questionnaire, does not change people's attitudes or provide them with information (Rose \& Grosvenor, 2001). The important point in this research is that each teacher answers particular questionnaire with possible answers "Agree, Disagree and I do not know". All of them are special need teachers in secondary mainstream 
schools. The last choice, "I do not know", was included in order to minimise the possibility of random selection. Some of the questions refer to the teaching methods that teachers use during the lesson so as to present the symptoms of intellectual disability. This allows for consistency and precision in terms of the wording of the questions, and makes the processing of the answers easier (Denscombe, 2003). However, Silverman (1997) has pointed out that the questionnaire is a tool of communication. In the questionnaire, there is a risk for participants to use the help of other people, but, on the other hand they feel more comfortable and free with the questionnaire than to express their thoughts in one-to-one interviewing (Frankfort-Nachmias \& Nachmias, 1992).

For a valid diagnosis concerning if the specific psychometric tool can detective intellectual disability, it was necessary to gather and assess information from all general areas of the teachers' practices. For this reason, the questionnaire was adjusted according to Greek reality. Closed questions were sent via internet with the help of Google drive, in order to save time. Furthermore, the Likert rating scale was used in order to determine how teachers agree or disagree with a series of statements, on a three-point rating scale. The main advantage is that the structure imposed on the teachers' answers provides the researcher with information which is of uniform length and in a form that lends itself nicely to be quantified (Hopkins, 2002).

Furthermore, special maintenance was given to the design of the questionnaire. The design of the questionnaire was formulated in such a way that it tested the theories on intellectual disability through statistical analysis and comparisons. Moreover, the questionnaire is highly functional, easy to fill in for the teachers and the sequence of the questions are understandable for the respondent. In addition, a covering letter was included so as to explain the purpose of this research and all these factors, contributed to higher response rates, validity and reliability.

\subsubsection{The collection of secondary data}

Secondary data is data that have been already collected by someone else (Denscombe, 2003). There are three main types of secondary data: documentary, multiple sources and survey; such as: reports, books, and academics' surveys. Secondary data help researchers to save money and time. Also, secondary data can be very effective in triangulating primary data that has been collected through questionnaires.

\subsubsection{Selecting samples}

Sample techniques enable a reduction in the amount of data needed to be collected, by considering a specific subgroup rather than a large amount of populations. This enables the researcher to save money and time (Rugg \& Marian, 2007).

There are two kinds of sampling techniques. The first is known as probability sampling

and the second as non-probability sampling. Probability sampling according to Denscombe (2003) is associated with a research method. Furthermore, it is based on the idea that the people or events that are selected as the sample are chosen because the researcher has some belief of the probability that these will be a representative cross-section of people or events in the whole population being studied.

\subsubsection{Response rate}

According to Denscombe (2003), the aim of a good research project is to have minimum non-responses and to have highest response rate possible. In a survey research, response rate refers to the total number of people who answered, divided by the total number in 
the sample (Rugg \& Marian, 2007). According to Healey (1991), for questionnaire surveys, a response rate of about 50 percent is the norm.

\subsubsection{Sampling technique}

A purposive sampling technique had to be implemented to collect data via questionnaires. The advantage of using purposive sampling is that it allows the researcher to select the sample that might answer the research questions and that is likely to produce the most valuable data (Denscombe, 2003). Purposive sampling was selected with a specific purpose in our mind, teachers in special schools. The particular sample was chosen because it was relevant to the topic of the investigation. However, according to Silverman (1997), samples cannot be considered to be statistically representative of the whole population. Based on Healey (1991), who suggests that a usual response rate is about 50 percent, 160 questionnaires were sent via Google drive to teachers, in order to ensure a minimum response rate of 70 questionnaires as the Economist (1997) suggested. Finally, for the validity of the research the participants were homogeneous, for instance all highly experienced teachers, as the sample selection was based on teachers' educational level and also all of them are working in special schools.

Last but not least, the selection of the teachers was made for the following reasons: those teachers are in the correct position to fill in the questionnaires because they they have experience and are specialized in special education.

\subsection{Data results}

\subsubsection{Analyzing quantitative data}

In order for the data to be analysed quantitative analysis was used because it uses numbers and can present findings in the form of graphs and tables. "Coding the data, in essence, entails the attribution of a group of data, with the express aim of allowing data to be analysed in quantitative terms and save time" (Denscombe, 2003). Quantitative data according to Denscombe (2003) are the following: (1) using diagrams, graphs, tables; (2) represented by using numbers.

Data in this survey were divided into eight categories, so as to be more understandable. These eight categories define out the teachers' Demographic Questions knowledge, Speedprocessing information, psychological characteristics-spiritual fatigue-social characteristics, concentration-attention, memory, linguistic-cognitive characteristics and mathematical characteristics. The finally category will point out teachers' general perception concerning the specific psychometric tool.

By comparing variables relationships and differences are examined. Firstly, by using tables the data is presented. Secondly, by using bar charts, the highest and the lowest values are shown. Thirdly, the pie charts data are presented as segments. Finally, data are entered in computer analysis by using the Excel Microsoft software.

\subsubsection{Findings}

Research findings outline the key findings from a study and illustrate the point where the reader is introduced to the data (Denscombe, 2003). 


\section{Results}

\subsection{Demographic questions}

The first five questions from the questionnaire examine the Demographic Questions of the participants. They are presented the Demographics of 70 participants. The aim of the research is the participation of at least 100 teachers. Demographics include gender, age, educational level, the school unit at which they are currently serving, and years of service. All of them are teachers who work with special needs students. These questions are presented in Figure 3.1 and 3.5 .

So far, 70 special needs teachers attend the research, 27 of them were men (40\%) and 43 of them were women (60\%). Of these, most were aged 35-44 (53\%). The majority of the participants (46\%) work in Gymnasium Middle School - Inclusion Classroom. Most of them have a Master's degree in Special Education or School Psychology (74\%), while few of them (11\%) have a PhD. Finally, 12 teachers stated that they have up to 4 years (13\%) of service, 48 of them work from 5-10 years (69\%), 9 of them work from 10-15 (17\%), while only one of them works more than 15 years (1\%) and none of them has 21 or more years of service (0\%).

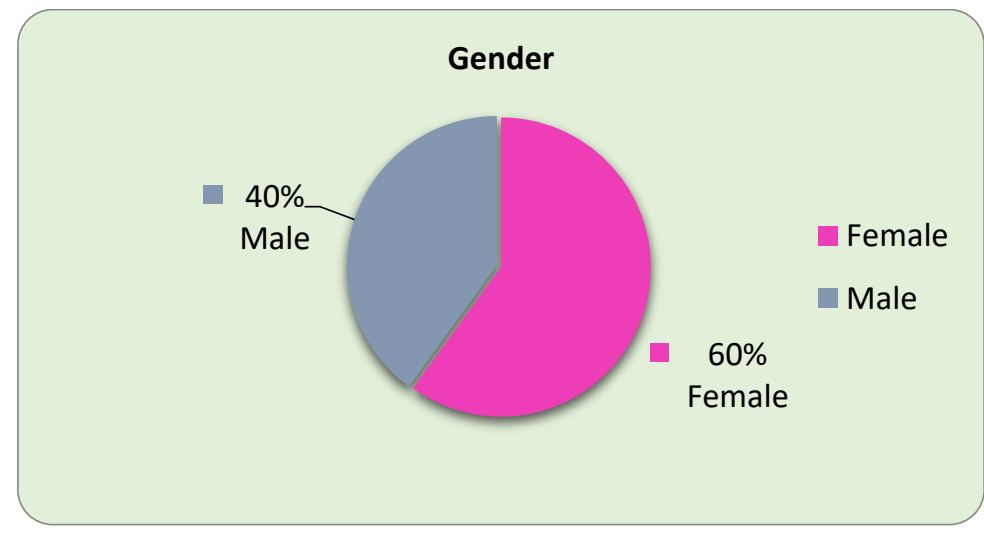

Figure 3.1. Gender of the participants

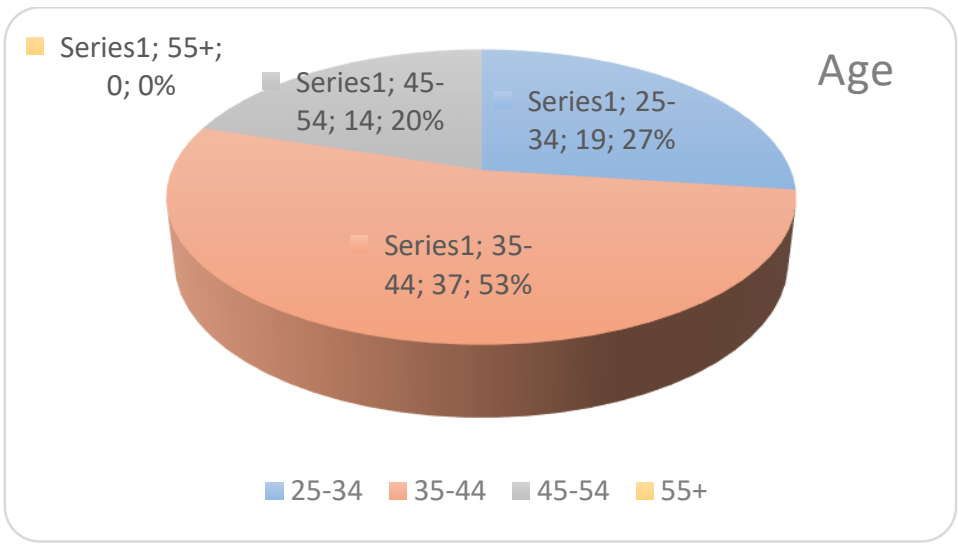

Figure 3.2. Age of the participants 


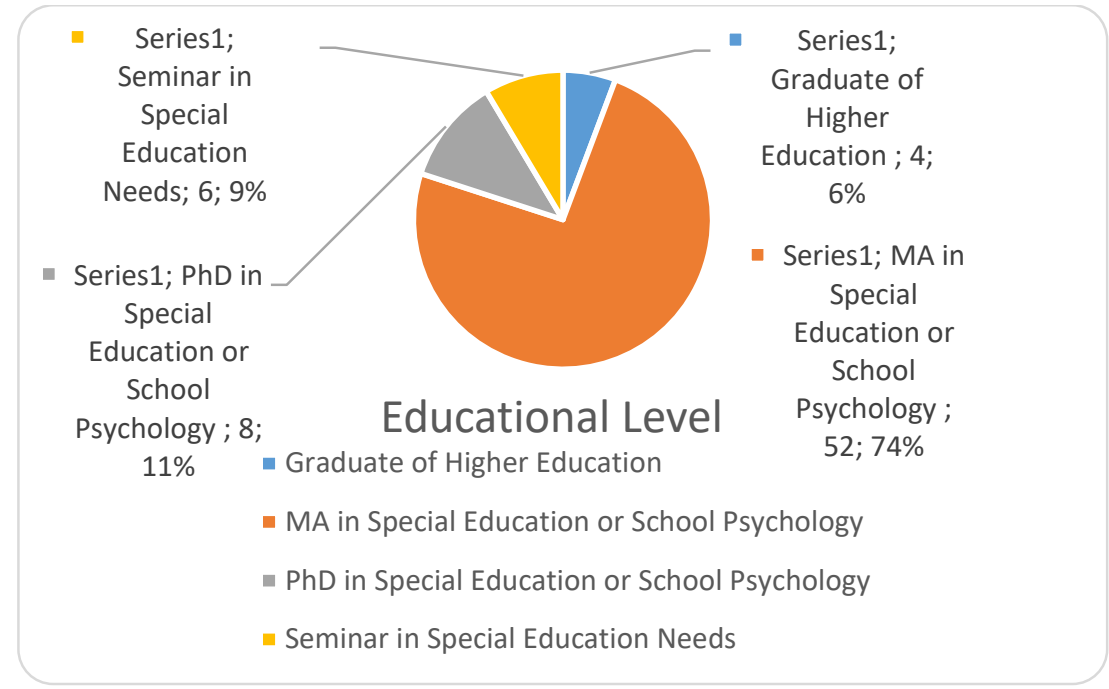

Figure 3.3. Educational level of the participants

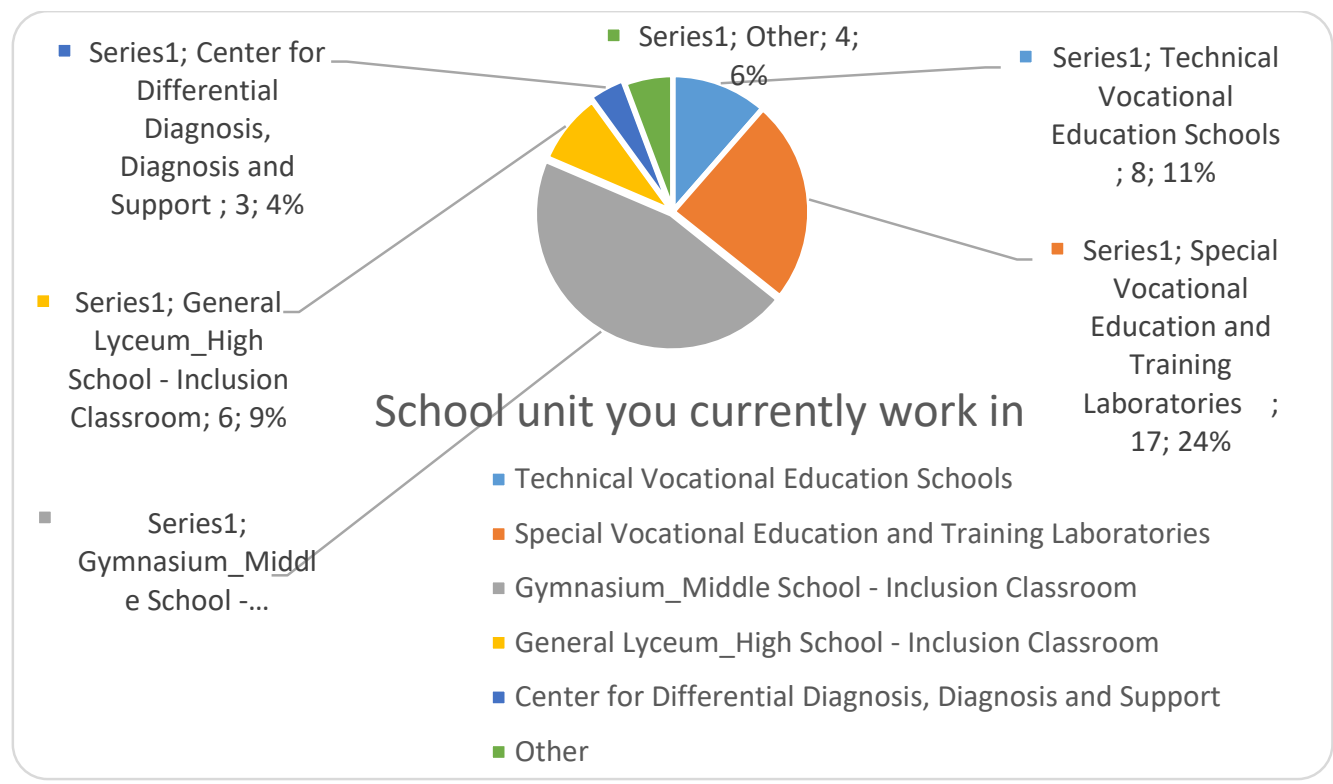

Figure 3.4. School unit the participants currently work in

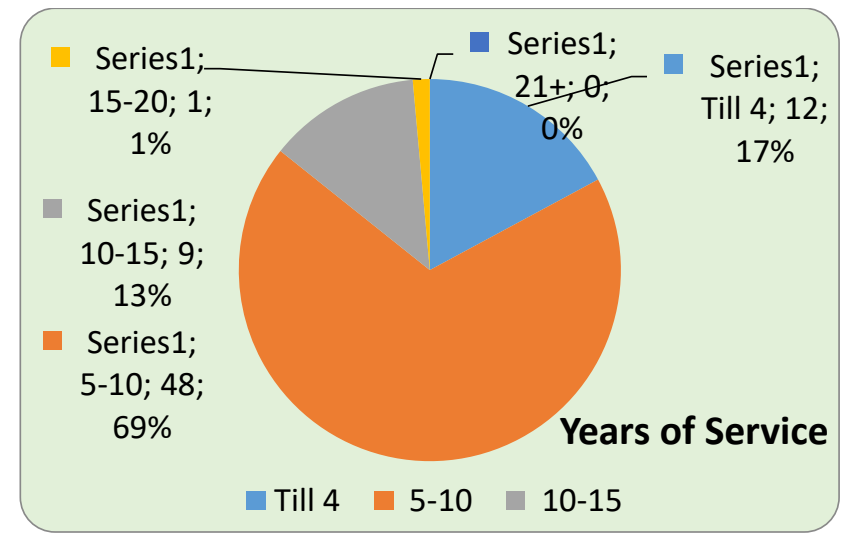

Figure 3.5. Years of service 


\subsection{Speed-Processing Information}

The sixth and the seventh questions from the questionnaire examined the teachers' opinion concerning the Speed-Processing Information from the psychometric test which had been given to them. These questions are presented in figures 3.6 and 3.7. It is characterized that students with intellectual disabilities need more time coding compared to student without disabilities. According to the literature, Panteliadou (2000), suggests that students with intellectual disability are characterized by a slowdown in the speed of processing information, mainly a quantitative and not a qualitative difference, in relation to the "typical" children. On the one hand, 62 per cent of the teachers agree that the specific test is appropriate in order to detect if a child with intellectual disabilities has a slow rate in processing and in organization, while another 34 per cent disagree with that statement. On the other hand, only 4 per cent of them answered "I do not know".

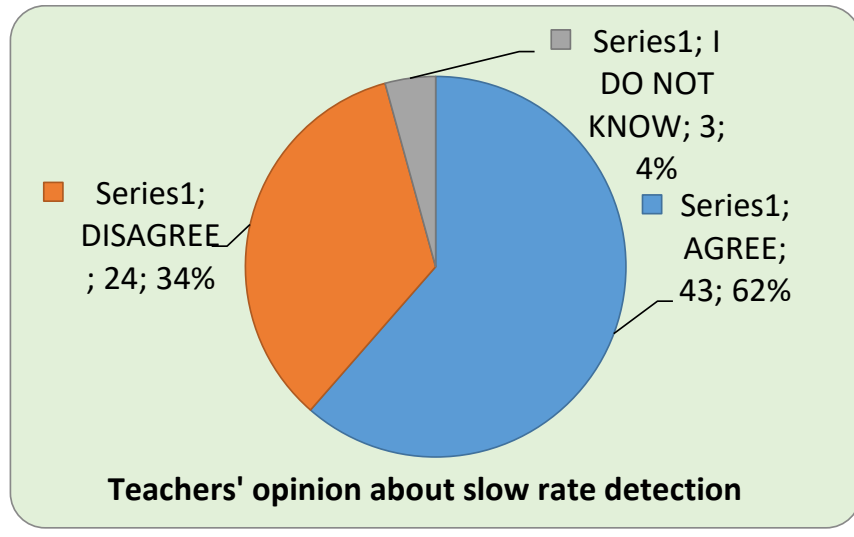

Figure 3.6. Teachers' perception on slow rate detection

Similarly, Figure 3.7, presents the teachers' opinion concerning time detection. $57 \%$ of them agree that the specific test can detect if the child with intellectual disabilities needs more time to decode (e.g. handwriting coordination) of known things, in relation to a child of the same age without intellectual disabilities. $40 \%$ of the participants disagree with that statement. Finally only $3 \%$ of them answered "I do not know". According to the literature, Hunt (1977), argues that children with mild intellectual disabilities need more time for processing and decoding of things which they know (Hunt, 1977) compared to their peers. Furthermore, Merrill (1990) pointed out that students with mental disability require more time than their schoolmates to automatically recall information, and therefore, they have more difficulties handling larger amounts of cognitive information at once.

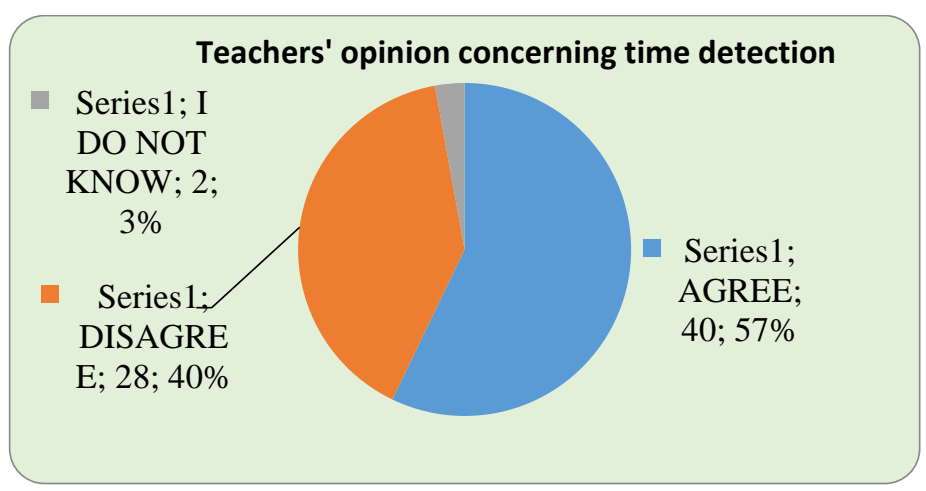

Figure 3.7. Teachers' perception on time detection 


\subsection{Psychological characteristics, spiritual fatigue and social characteristics}

Students with intellectual disability face social and psychological difficulties. Panteliadou (2000), reported that a student with intellectual disability is characterized by a mental fatigue, much higher than the "typical" children, and easier regression in earlier stages of cognitive and psycho-emotional development. By examining teachers' opinion regarding the mental fatigue detection; it is too significant to be told the strong correlation between the answers which has been found. A total of $47 \%$ of the teachers believe that the specific psychometric tool can detect if a student presents mental fatigue. Moreover, about $44 \%$ believe that this test cannot detect mental fatigue. Finally, only six teachers answered "I do not know" specifically, a percentage of $9 \%$ (Figure 3.8 ).

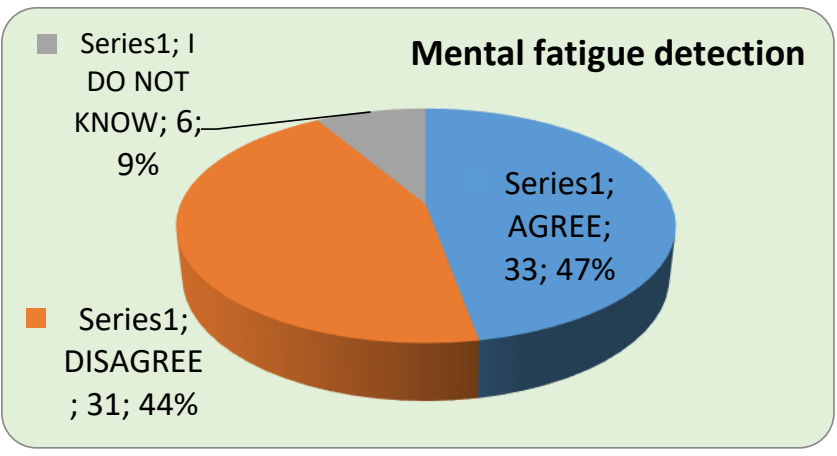

Figure 3.8. Teachers' perception on mental fatigue detection

Students with intellectual disability have difficulties in thinking before acting. To begin with, the majority of teachers, about $79 \%$ agree that through this psychometric tool it can be detected if children with intellectual disabilities can think before they act. Specifically, 79\% of the teachers answered agree, 21\% of them answered disagree while none of them answered I do not know (Figure 3.9). These results correspond with Kroustalakis (1990), who state that students with intellectual disability have not the ability to control their behavior and they act before thinking. Additionally, they are characterized by anxiety, impulsiveness and low self-esteem.

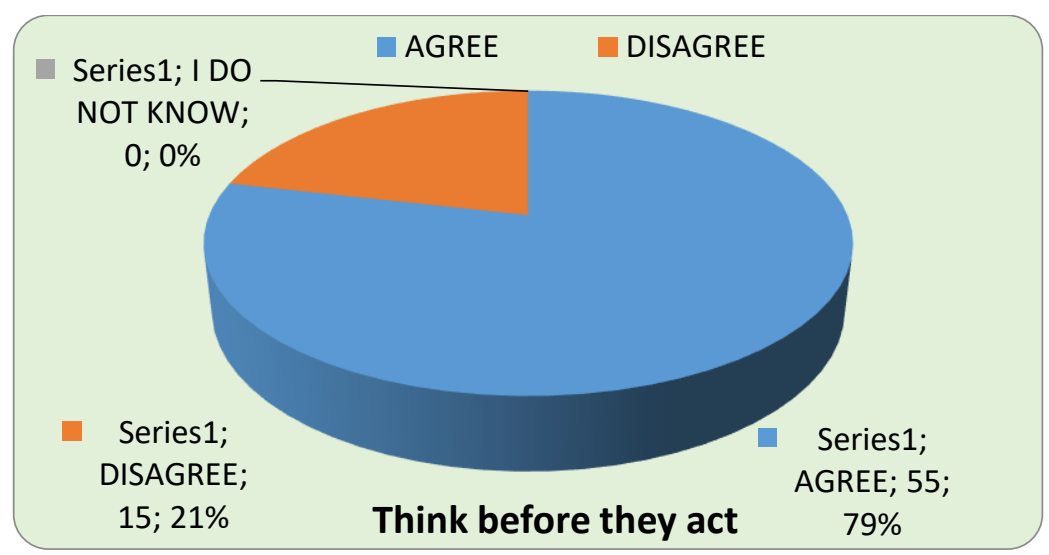

Figure 3.9. Teachers' perceptions whether students with intellectual disability think before they act

Moreover, $63 \%$ state that the specific psychometric tool detects self-awareness and low self-esteem posed by students with intellectual disabilities, whilst $37 \%$ of the teachers' disagree with the specific statement (Figure 3.10). This comes in accordance with Paraskevopoulos (1980) who argues that children with intellectual disability face inability to take action or follow commands with a consistent and independent manner. The feeling of inferiority and low self- 
esteem stems from the disappointment which is obtained at school where the demands and expectations are usually higher from their potential. Moreover, they have low or no expectations of success due to their cognitive difficulties. Finally, they do not have a coherent personality, and they do not have the skills of self-awareness, which means that they have low self-esteem.

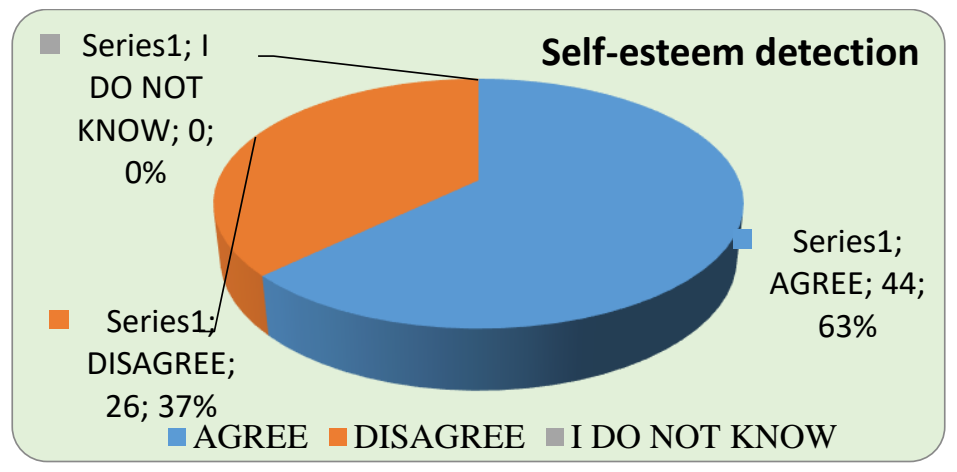

Figure 3.10. Teachers' perception on self-awareness and low self-esteem detection

\subsection{Concentration-attention}

Another feature which was examined in the research was teachers' opinion about detection of concentration-attention (Figure 3.11). According to the literature, Polychronopoulou (2001), an important characteristic of those students is the maintenance of their attention to an activity. Moreover, she argues that they have poor visual-motor coordination.

Furthermore, according to Westling (1986), students with intellectual disabilities face difficulties in the attention of appropriate dimensions such as shape, size, position, color and weight of a particular object. In addition, these children find it difficult to notice the correct dimensions of the objects, which will provide them with the necessary information for a successful distinction between them. Furthermore, Barbas (2008), argues that children with mild mental disability face problems in gathering information, in reading and in other cognitive functions.

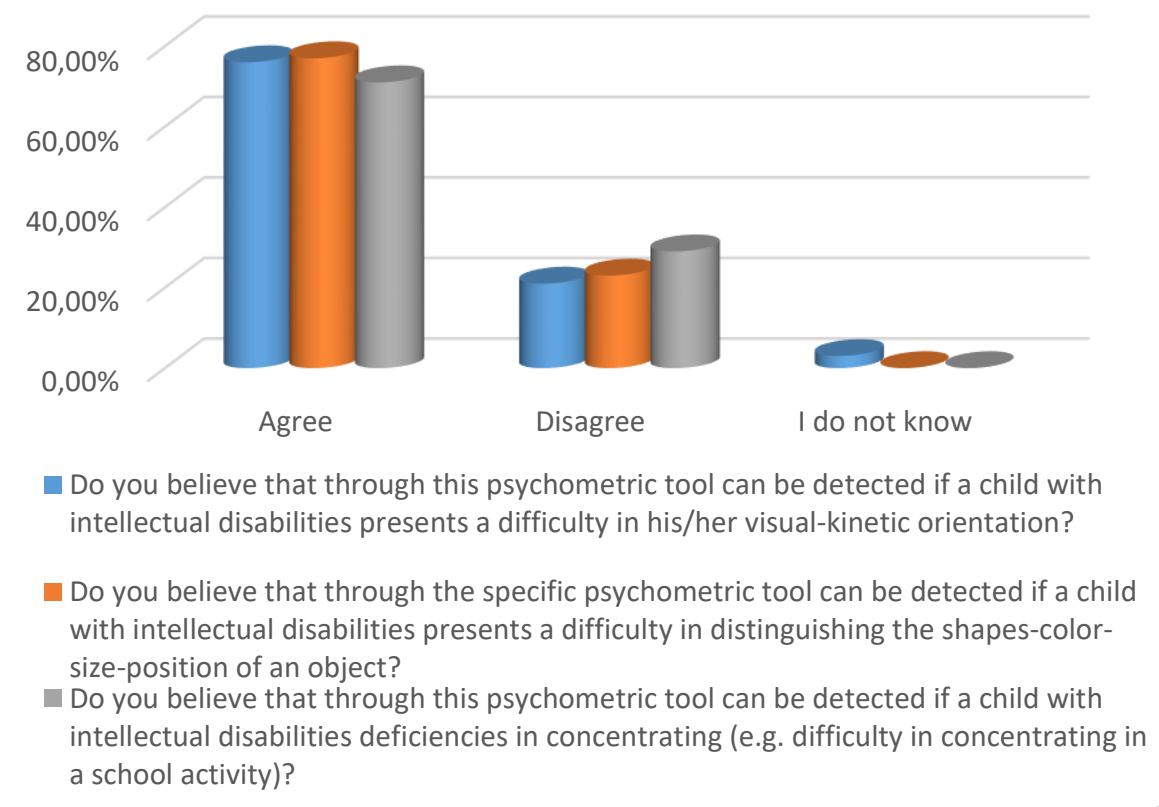

Figure 3.11. Total comparison concerning concentration-attention 
Finally, from the findings it is concluded that teachers have remarkably positive perceptions on the specific psychometric test, which can help in order to detect if a student with intellectual disability present difficulties concerning concentration and attention. Specifically, $76 \%$ of them believe that the specific tool is able to detect if a child present difficulties in visualkinetic orientation, while $21 \%$ tent to disagree with that statement and $3 \%$ answered "I do not know". Furthermore, concerning the question "if you believe that through the specific psychometric tool can be detected if a child with intellectual disabilities presents a difficulty in distinguishing the shapes-color-size-position of an object" $77 \%$ agree and $23 \%$ of them disagree. Last but not least, $71 \%$ of the participants agree that through this psychometric tool can be detected if a child with intellectual disabilities presents deficiencies in concentrating (e.g. difficulty in concentrating in a school activity) and $29 \%$ have the opposing opinion.

According to the results from the three above questions we come in a correlation from the Wisc test which mentions that the practical part of the test is related to visual perception, visual-motor organization and the working method of constructions. The Wisc test examines the ability for proper provision of images, image completion, and image composition by the use of colored cubes, image reconstruction, and mazes.

\subsection{Memory}

Students with intellectual disability exhibit memories difficulties. The majority of the participants, about 66\% agree that through this psychometric tool can be detected if a child with intellectual disabilities has disadvantages in different areas of memory (dictionary part of the test - practical part of the test). However, 33\% of them have the opposite opinion, while only $1 \%$ answered "I do not know" (Figure 3.12)

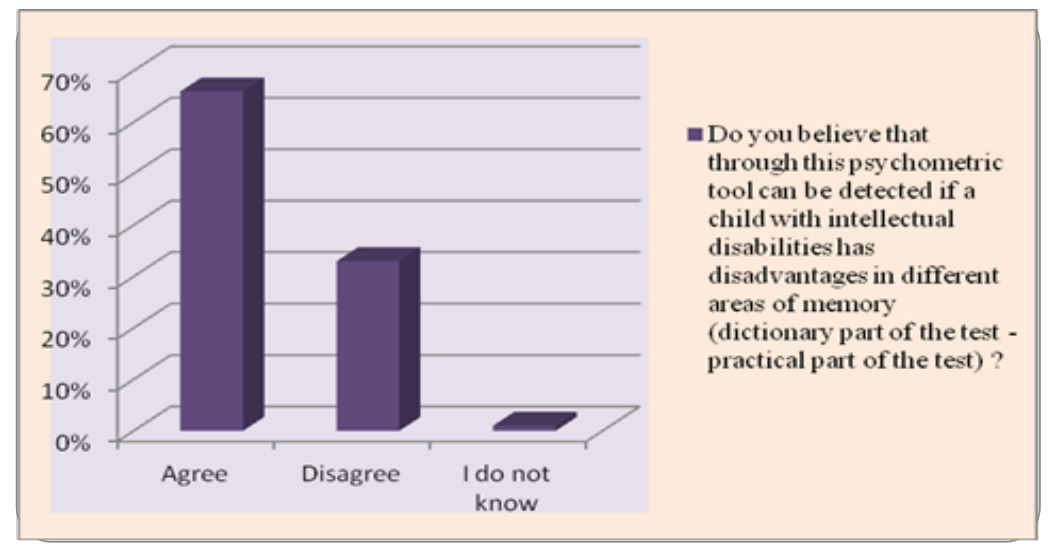

Figure 3.12. Teachers' perceptions on memory detection

Moreover, a remarkable percentage of $74 \%$ state that the specific test can help in order to detect if a child with intellectual disabilities experiences difficulties in memorizing words, schematics of concepts, images, and symbols in relation to a child of the same age without intellectual disabilities. Only $22 \%$ of the participants disagree with that statement and $4 \%$ of them answered "I do not know" (Figure 3.13). According to the literature Hoover and Wade (1985), pointed out that student with intellectual disabilities fail to remember words and concepts. Vasileiou (1998), argues that their perceptual ability and memory are at a low level, with difficulties in concentrating, in understanding abstract concepts, in numbers, in comparisons, in symbols, and they also face difficulties in conquering space, time, quantity, and size. 


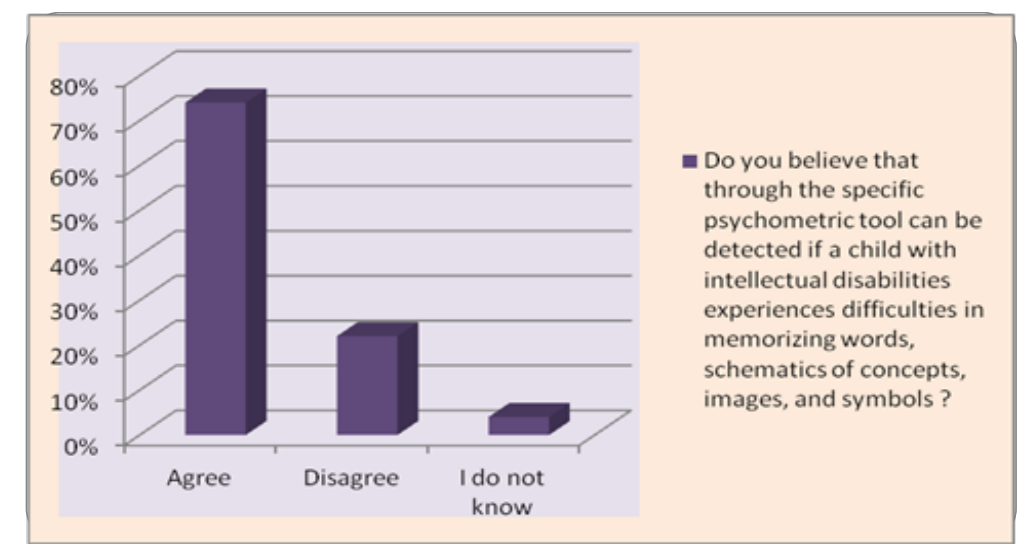

Figure 3.13. Teachers' perception on memorizing words, schematics of concepts, images, and symbols detection

Teachers' perception concerning whether this psychometric tool examines if the lack of strategic thinking is directly related to short-term memory, the majority of teachers, a percentage of $71 \%$, agree with that statement. On the other hand, $26 \%$ of them believe that it is not an appropriate psychometric tool while only, 3\% answered "I do not know" (Figure 3.14).

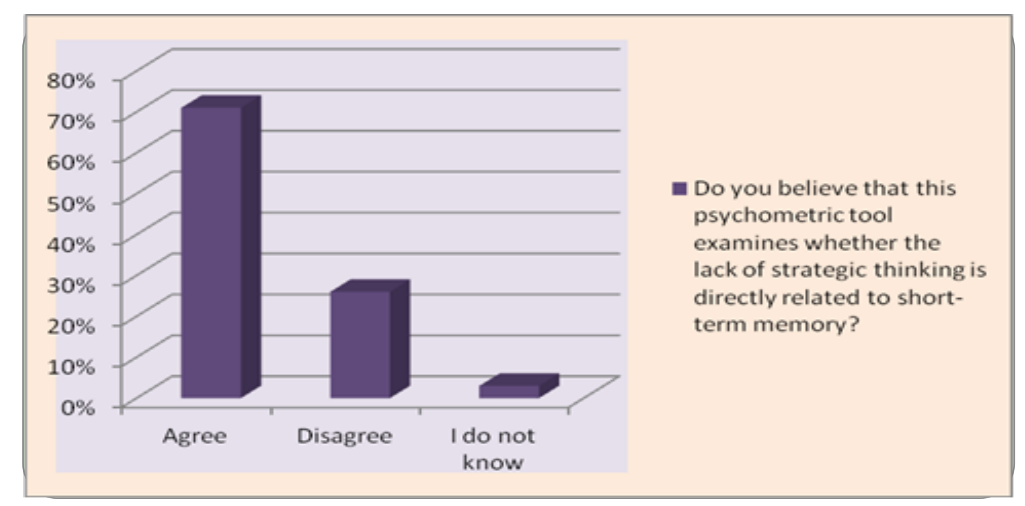

Figure 3.14. Teachers' perception on short-term memory detection

\subsection{Linguistic-Cognitive Characteristics}

At the beginning of their school year students with intellectual disabilities face difficulties especially in reading, writing and arithmetic. Another critical factor that has been examined concerning teachers opinion is whether through this psychometric tool can be detected if a child with intellectual disabilities has a lower intellectual level related to a child of the same age without intellectual disabilities (Figure 3.15). A total of $73 \%$ of respondents recognise that this tool can be useful in order to detect the intellectual level. Furthermore, $27 \%$ has a positive opinion about it. Concerning Polychronopoulou (2001), a specific characteristic of students with intellectual disability is that their intellectual level is lower than required, in order to understand the subjects being taught, and they present various difficulties such as learning and attention. 


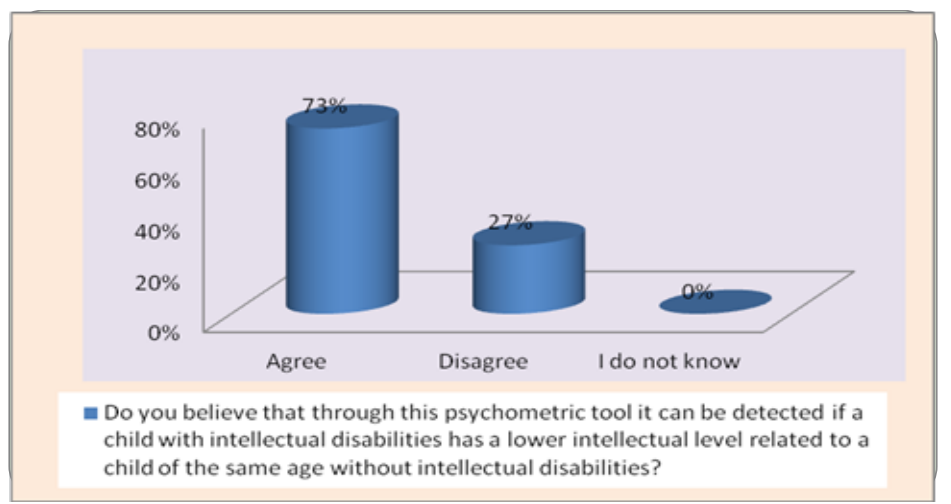

Figure 3.15. Teachers' perception on intellectual level detection

There is a positive connection between the two questions that follow, because both of them are related to language and vocabulary difficulties.

Firstly, a percentage of $76 \%$, agree that this tool is an appropriate one, in order to detect if a child with intellectual disabilities presents language difficulties (pronunciation of words, difficulty in articulation, missing words, distortion or adding another word). As illustrated in the research of Soulis (2002), students with intellectual disability present speech disorders (delayed speech initiation). Furthermore, Dobbing (1984), argues that children with intellectual disabilities face many problems in their linguistic development: problems in the pronunciation of words, difficulty in articulation, substitution, omission, addition or distortion of sounds, problems in understanding the grammar of the written and the spoken word. On the other hand, $24 \%$ of the teachers state that this tool is not appropriate to detect language difficulties (Figure 3.16).

Moreover, the majority of the participants, a percentage of $81 \%$, agree that with the help of this psychometric tool, can be detected if a child with intellectual disabilities presents poor vocabulary (finding the right word meaning). Only 19\% of the participants disagree with that statement (Figure 3.16).

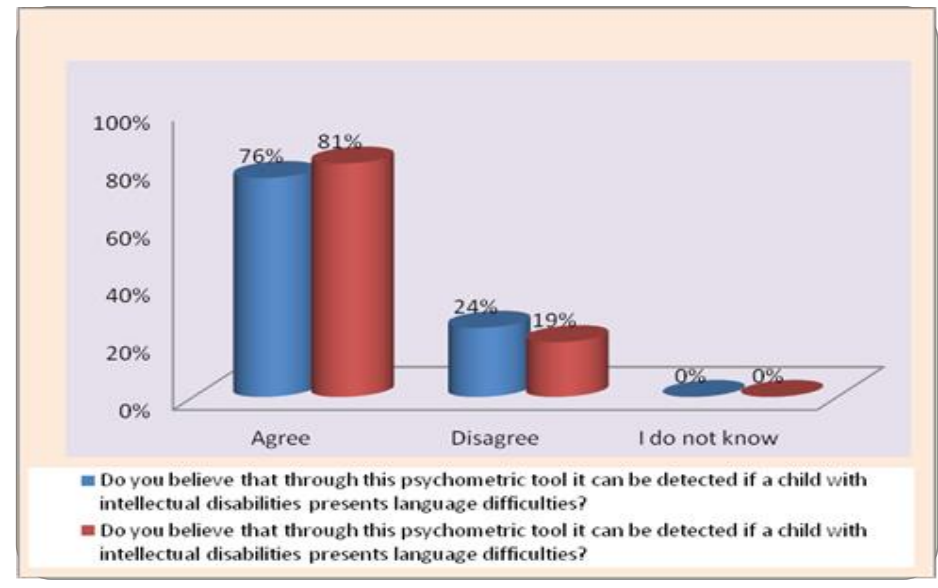

Figure 3.16. Teachers' perception on language and vocabulary difficulties detection

There is a positive correlation between the two questions that follow, because both of them are related to the writing and speaking characteristic of a child with intellectual disability.

The teachers' opinion concerning whether this psychometric tool can detect if a child with intellectual disabilities presents poor organization in thinking and speech (both in writing and speaking) was also examined. The majority of the teachers, a percentage of $79 \%$ agree, whilst, $21 \%$ of the teachers disagree with the statement (Figure 3.17). Specifically, almost four in every 
five teachers have a positive opinion. Soulis (2002), argues that these children also face problems in the organization of information and in general thinking strategy. The lack of strategic thinking is connected to the problem they face in their short term memory.

A remarkable percentage of $89 \%$ of the sample state that through this psychometric tool can be detected if a child with intellectual disabilities faces difficulties in understanding texts (finding a hero, central idea of a text, distinguishing significant from insignificant information) (Figure 3.18). Specifically, almost nine in every ten teachers agree with that statement (89\%). However, there is also a small percentage of participants (11\%), who believe that this test is not appropriate in order to detect difficulties in understanding texts. Soulis (2002), pointed out that children with intellectual disability present deficit understanding in text (symbolic content, consequences of events).

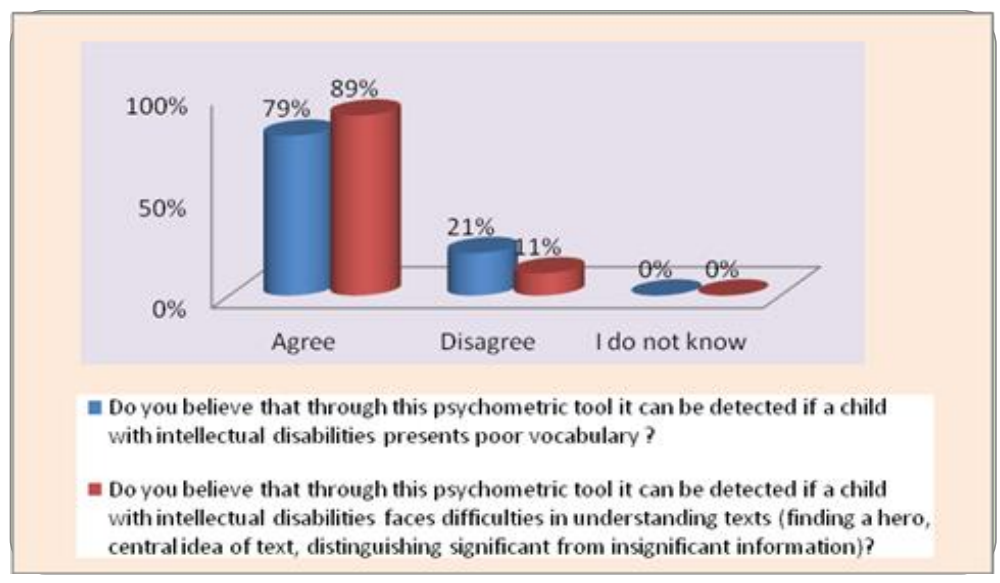

Figure 3.17. Teachers' perception on writing and speaking detection

Last but not least, teachers' perception concerning whether this psychometric tool can detect if a child with intellectual disabilities can generalize his general knowledge in his daily life has been also examined. The percentage of $59 \%$ of the sample has a positive opinion about it, whilst, 37\% disagree with that statement (Figure 3.18). According to Soulis (2002), a characteristic of students with intellectual disability is that they face problems in the organization of information and in general thinking strategy.

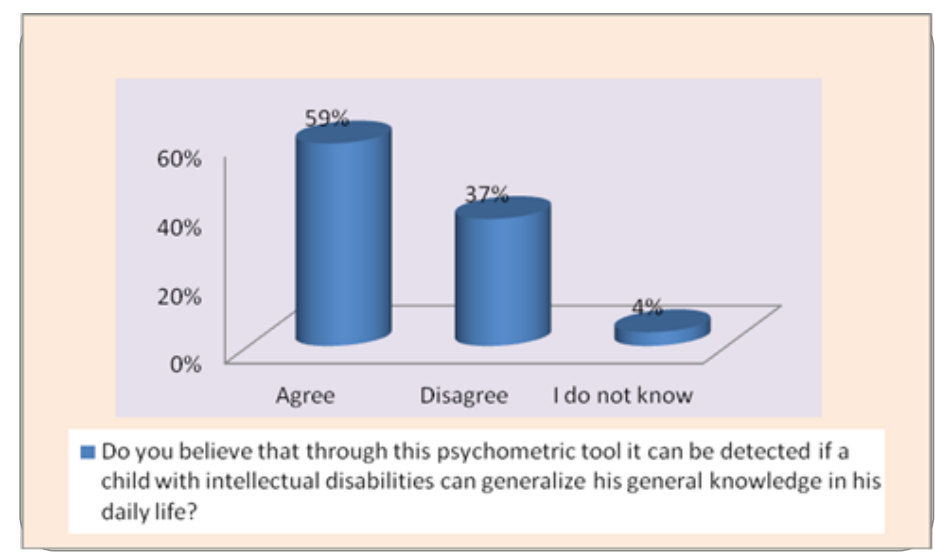

Figure 3.18: Teachers' perception on general knowledge detection 


\subsection{Mathematical characteristics}

There is a positive correlation between the three questions that follow, because they are related to the mathematical characteristics of students with intellectual disabilities.

According to Christakis (2006), students with intellectual disabilities face difficulties in solving mathematical problems in editing geometric symbols, in understanding abstract concepts, in mathematical thinking and in understanding concepts with visible morphological characteristics. According to Hoard et al. (1999), students with intellectual disabilities face difficulties in developing mathematical skills and they need special attention in their acquisition. Moreover, according to DSM-IV, the disorder of mathematics, as it is called, is characterized by a reduced ability of the child for mathematical computations and operations (e.g. understanding mathematical terms, acts, concepts or symbols, correct number copying and execution of specific acts, addition with carrying, etc.). Last but not least, Johnson and Myklebust (1967), argue that difficulties in mathematics may affect the whole range of mathematical knowledge, from numbering to problem solving. In addition to the above mentioned mistakes, children with intellectual disabilities face difficulties in numbering and in measuring, ascending or lowering the line (one, two, two, three, etc.).

Firstly, a remarkable percentage of $90 \%$ the sample state that through this psychometric tool can be detected if a child with intellectual disabilities presents difficulties in understanding symbols and in mathematical terms. However, there is also a small percentage of 10\% who has an opposite opinion (Figure 3.19).

Secondly, a percentage of $84 \%$ agree that through this psychometric tool can be detected if a child with intellectual disabilities experiences difficulties in calculating mathematical problems (understanding, problem-solving strategies). On the other hand, $16 \%$ of the teachers state that this test is not appropriate in order to detect difficulties in calculating mathematical problems (Figure 3.19).

Last but not least, Figure 3.19 also presents the teachers' perceptions whether this psychometric tool can detect if the child with intellectual disabilities presents difficulties in performing certain mathematical operations (addition, subtraction, multiplication, division). On the one hand, $87 \%$ of the teachers agree, while a percentage of $13 \%$ disagree. On the other hand, none of them answered "I do not know".

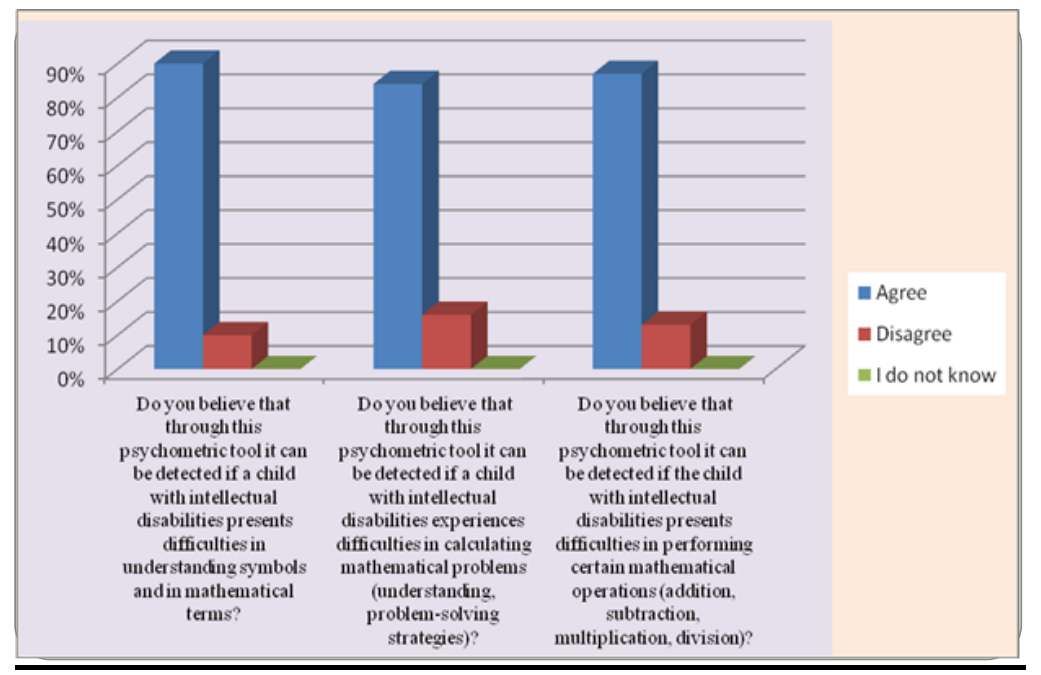

Figure 3.19. Teachers' perception on mathematical characteristic detection 


\subsection{General perceptions}

The main finding in this research ( $26^{\text {th }}$ question), is that the specific psychometric tool can help in diagnosing intellectual disabilities (Figure 3.20). 91\% of the teachers agree that the specific test is an appropriate tool in order to detect intellectual disability, whereas just a percentage of $9 \%$ has an opposite opinion. The conclusion is that there is a large deviation between "Agree" and "Disagree" statement.

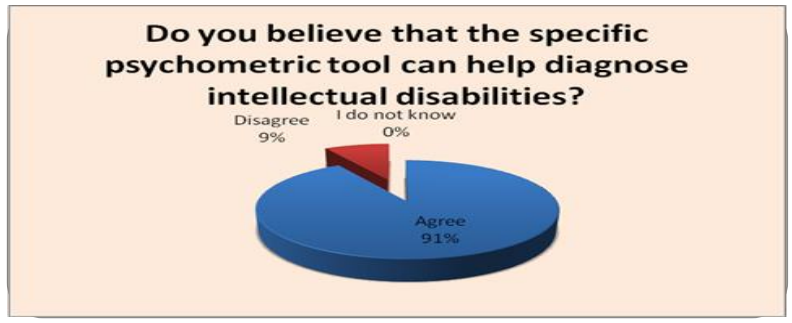

Figure 3.20. Teachers' perception whether the specific psychometric tool can help in diagnosing intellectual disabilities

The teachers who took part in the specific research, they also answered in an open question, the following one: "Do you believe that is important some parts of the test to be changed?" Specifically $84 \%$ argue that the form of the test is satisfactory and only $16 \%$ from them answered that the test is important to be changed (Figure3.21).

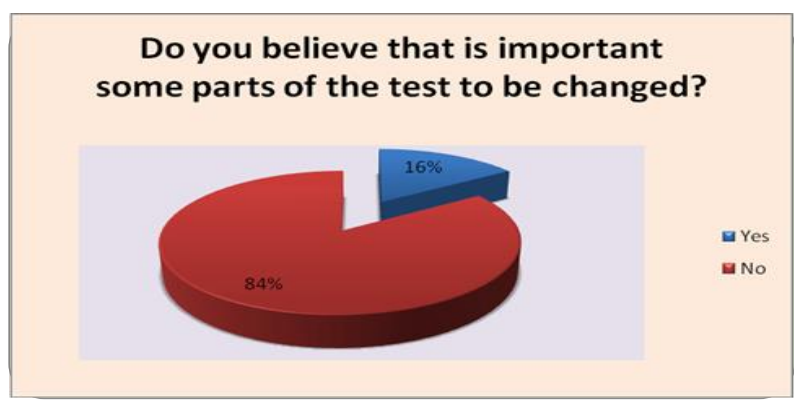

Figure 3.21. Teachers' perception on changes concerning the psychometric test

\subsection{Comparisons and conclusions}

\subsubsection{Comparing highest and lowest values}

The highest value in the general question is observed in the statement whether the specific psychometric tool can help in diagnosing intellectual disabilities. A percentage of 91\% of the teachers agree that this test can detect intellectual disability. The lowest value is zero and is detected only in the answer "I do not know". Some of the questions with the lowest value are: the general question and the statement whether the teachers believe that through this psychometric tool can be detected if a child with intellectual disabilities presents difficulties in understanding symbols and in mathematical terms (these two questions were chosen, because they also include the highest value of the statement "Agree").

\subsubsection{Analysing results}

The highest value is observed in the general question, with $91 \%$ of the participants, and the lowest value is detected in the question of psychological characteristics, which is whether the teachers believe that this psychometric tool can detect the mental fatigue of children with 
intellectual disabilities with a percentage of $47 \%$. Most significantly is that the general question includes also the lowest rate, with a percentage of $9 \%$, and moreover, the other question, has also the highest value with $44 \%$ (Figure 3.22). The above totals suggest that firstly, almost everyone agree that the specific psychometric test can detect intellectual disability. Secondly, it shows that there is a strongly correlation between the answers of the teachers concerning mental fatigue.

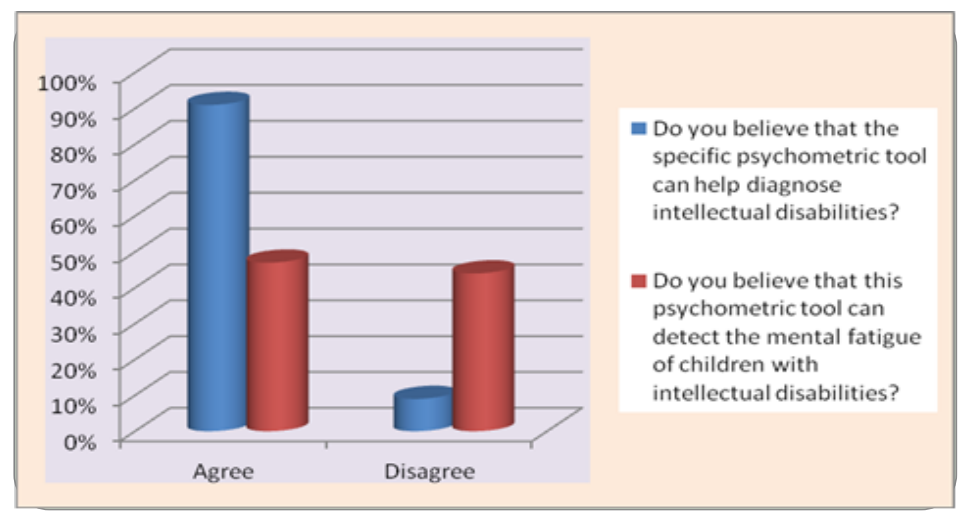

Figure 3.22. Highest and lowest values

\section{Discussion and conclusion}

This survey interprets whether the psychometric test that have been constructed by me, is an appropriate tool in order to detect intellectual disability regarding to teachers' opinion. With reference to the seven broad categories of the research, the sample which was the special school teachers appeared to argued that the specific test is an appropriate tool in order to detect psychometric test. From the results of the linguistic-cognitive and mathematical categories, we conclude that this tool is able to diagnose intellectual difficulties.

In this study, all the data are divided into six categories so as the validity of the results to be more understandable: speed-processing information, psychological characteristics-spiritual, fatigue-social characteristics, concentration-attention, memory, linguistic-cognitive characteristics and mathematical characteristics. A general perception and an open question are also included.

From the teachers' answers as most people agree that the particular psychometric is suitable for diagnosing a mental one, the time period of the results of the diagnostic assessment of the children will be limited. Since it is necessary to diagnose and formulate the most appropriate methods of intervention. It will also give an insight into the current situation of the child in important areas and areas that need appropriate and immediate intervention.

From the teachers' answers as most of them agree, we conclude that this psychometric tool is suitable for the diagnosis of intellectual disabilities. Furthermore, it will give an insight into the current situation of the child in important areas and areas that need appropriate and immediate intervention.

The diagnosis of intellectual disability through this psychometric tool is necessary for the school performance of pupils with mental retardation. Depending on the degree of intellectual disability, students will join either regular school in inclusion classrooms or special schools where their education will be tailored to the student's needs. Thus, a proper special education will be developed in order their personality and their skills to be improved, and pursue their future professional training in order to achieve equal social development. 


\section{References}

Barbas, C. (2008). What is true, the pupil with special educational needs? Society and Mental Health, 7, 3852.

Christakis, K. (2006). Education of students with difficulties: Introduction to special education. Athens: Atrapos.

Denscombe, M. (2003). The good research guide for small-scale social research projects. Maidenhead: Open University Press.

Dobbing, J. (1984). The pathogenesis of microcephaly with mental retardation. Effects of prenatal irradiation with special emphasis on late effects. European Atomic Energy Community, pp. 109-212.

Economist (1997). The economist numbers guide: The essentials of business numeracy ( $3^{\text {rd }}$ ed.). London: Profile Books.

Frankfort-Nachmias, C., \& Nachmias, D. (1992). Research methods in the social sciences. London: Edward Arnold.

Healey, M. J. (1991). Obtaining information from businesses. In: M. J. Healey: Economic Activity and Land Use: The Changing Information Base for Local and Regional Studies. Harlow, Longman, pp. 193-250.

Hoard, M. K., Geary, D. C., \& Hamson, C. O. (2000). Numerical and arithmetical cognition: Patterns of functions and deficits in children with learning disability. Journal of Experimental Child Psychology, 77, 236-263.

Hoover, J. H., \& Wade, M. G. (1985). Motor learning theory and mentally retarded individuals: A historical review. Adapted Physical Quarterly, 2, 228-252.

Hopkins, D. (2002). A teacher's guide to classroom research (3rd ed.). Maidenhead: Open University Press.

Hunt, J. M. (1977). Intelligence and experience. New York. Ronald Press.

Johnson, D., \& Myklebust, H. (1967). Learning disabilities: Educational principles and practices. New York: Grune \& Stratton.

Kroustalakis, C. (1990). Children with special needs. Athens.

Merill, E. C. (1990). Resources allocation and mental retardation. International Review of Research in Mental Retardation, 16, 51-88.

Panteliadou, S. (2000). Learning difficulties and education. Athena: Ellinika Grammata.

Paraskeuopoulos, I. N. (1980). Mental retardation, differential diagnosis, reason - prevention, treatment psychologist. Athens: Organization Publications Textbook.

Polichronopoulou, S. (2001). Children and adolescents with special needs and possibilities (Volume II). Mental retardation Athens: Atrapos.

Rose, R., \& Grosvenor, I. (2001). Doing research in special education: Ideas into practice. London: David Fulton Publishers.

Rugg, G. \& Marian, P. (2007). A gentle guide to research methods. Maidenhead: Open University Press.

Saunders, M., Lewis, P., \& Thornhill, A. (2003). Research methods for business students (3rd ed.). Pearson Education Limited.

Silverman, D. (1997). Qualitative research: Theory, method and practice. London: SAGE. 
A. Mourelatou \& M. Zamfirov - Special Needs Teachers' Perceptions on the Psychometric Test

Soulis, S. (2002). Pedagogy of accession. Athina: Typothito.

Vasileiou, K., (1998). The trainable mentally retarded children and adolescents. Athens: Greek Letters.

Westling, D. L. (1986). Introduction to mental retardation. New Jersey: Prentice Hall.

C O A S 